\title{
Square dancing for middle-aged and old reaction, balance and coordination
}

\author{
Jing Li ${ }^{1}$ ' Wenbin Liu ${ }^{{ }^{*}}$ \\ ${ }^{1}$ Department of Basics, Wuhan Technology and Business University, Wuhan, China \\ *Corresponding Author: Wenbin Liu
}

Keywords: Square dancing; Middle-aged and old; Reaction time; Ability to balance; The coordinated ability

\begin{abstract}
Adopts questionnaire survey, literature, and experimental research methods, such as older women groups of Wuchang district in Wuhan sports participation after the body's reaction effect, balance and coordination of related research. The main conclusion is that the elderly sports population in Wuhan has further development space, and the development of sports activities, the development of the organization and the construction of site facilities need to be more targeted. The main factors that affect the sports participation of the elderly are physical illness, personal interest and the drive of family and friends. Most elderly people have the need for sports activities, and most want to increase and improve the sports organizations in the community, access to fitness knowledge and physical activity guidance, and targeted physical fitness tests and inspections. Recommendation: vigorously develop sports organizations in the community and support the financial and policy aspects; we will strengthen the construction and renovation of community sports facilities, expand access to fitness knowledge and information for the elderly, and increase the number of social sports instructors in community sports organizations. We will actively carry out the national physical fitness testing of elderly people in the community, and appropriately increase targeted testing programs.
\end{abstract}

\section{RESEARCH PURPoSe}

With the development of the social productivity level and the advancement of science and technology, the people's living standard has been improved, and the problem of the aging of the population has become increasingly serious. After into old age, body tissues and organs and the body gradually degraded, the effect of the external environment adaptability is also gradually decline, and the body resistance decline, lead to the prevalence of various diseases rise gradually, at the same time can also cause a series of complications. In addition to vulnerable cardiovascular diseases, respiratory diseases and some chronic diseases, the problems of wrestling and fracture in older adults are becoming increasingly prominent. According to the relevant literature study, we found that the square dance was in good condition in the field of mass sports in China. For middle-aged and old problem such as prevention of falls and broken bones, there are a lot of research has shown that involved in the square dance movement for a long time, can effectively regulate and improve the elderly cardiovascular system and respiratory function, and to help the elderly to improve reaction time and balance ability, coordinating ability and other physical qualities. Therefore, this makes the research of this paper more pertinence and necessity, and has stronger practical significance.

This topic tries to insist on whether the square dance exercise can effectively improve the reaction ability, balance ability and coordination ability of the elderly, and slow down the decline of the body function. We hope to guide the middle-aged and old people to choose the best form of 
exercise, improve the health benefit of the middle-aged and elderly people, and drive more people to the sport.

\section{RESEARCH OBJECTS AND METHODS}

\section{A. The research object}

TABLE I. RESEARCH OBJECT DISTRIBUTION

\begin{tabular}{llllll}
\hline $\begin{array}{l}\text { Group } \\
\text { (Person) }\end{array}$ & Sex & $\begin{array}{l}\mathbf{5 5 - 5 9} \\
\text { (Years Old) }\end{array}$ & $\begin{array}{l}\mathbf{6 0 - 6 4} \\
\text { (Years Old) }\end{array}$ & $\begin{array}{l}\mathbf{6 5 - 7 0} \\
\text { (Years Old) }\end{array}$ & Total \\
\hline $\begin{array}{l}\text { Experimental } \\
\text { Group }\end{array}$ & Male & 10 & 8 & 6 & 24 \\
& & & 3 & 2 & 8 \\
Matched & Female & 3 & 9 & 5 & 23 \\
Group & Male & 9 & & 2 & 8 \\
Total & Female & 3 & 3 & 15 & 63 \\
\hline
\end{tabular}

As shown in table 1: selection of Wuchang district of Wuhan city 55-70 - year - old age of the elderly, a total of 63 people, will insist for a long time to square dance exercise, and exercise more than three times a week or more, practice time more than $30 \mathrm{~min}$ in old people was divided into the experimental group. The elderly who had little or no physical activity were divided into a control group.

\section{B. The research methods}

1) Document method

By browsing China journal net (www.cnki.com), China academic network (wwwtiyujie.com) website, such as system refer to 1997-2013 about elderly sports exercise, and understand the research situation, and makes references to the sports physiology, sports measurement and evaluation, such as books, mainly from the physiological function in the elderly, focuses on the physical quality research, read the sanda journals, academic papers, magazines, journals and so on more than 20, makes every effort to have a comprehensive understanding to this topic research.

2) Questionnaire survey

A questionnaire survey was conducted among 32 participants in the survey in the area, and the basic exercise of the experimental group was understood. A total of 32 questionnaires were distributed and 32 questionnaires were collected. Among them, the effective questionnaires were 30 points, the recovery rate was $100 \%$ and the efficiency was $93 \%$.

3) Experimental method

Test method: the subjects placed one finger in the sensor area of the tester and two eyes were on the front row of red light.When the lights are red, the beginning of the test subjects were used in the hand quickly press the red button in the induction and quickly return to, in turn into a set of 10 times, "S (SEC)" as the unit to record the results, keep two decimal places. The best results were tested 2 times, and data analysis was performed on average responses.

Don't close your eyes and stand on one foot. The subjects stood with their hands on their hips, standing on one foot and leaving the ground. Start the time from the foot to the ground, stop the clock until it is down or stand, and record the time of standing on your feet. S (second), regardless of decimal. Precautions: the elderly should be treated with high blood pressure and normal vertigo. They should be protected when necessary. 
Hand coordination ability test: the target light spot is red when the two-handed controller starts, and the timer number is 0 . Set the target light spot on the hand adjuster to the starting position. The subjects followed the trajectory of the target, but did not go beyond the trajectory movement, and required a quick and accurate one-week operation. You can practice three times and master the basic rules. Then you can start the experiment and record the results twice.

4) Mathematical analysis

All will collect survey data, the use of Excel software and SPSS software to complete data statistics processing, by $\mathrm{T}$ test analysis of long-term adherence to the square of the same age, and sex dance exercise and did not take part in physical exercise of the elderly in the reaction time, balance, coordination ability whether there was a significant difference.

\section{RESULTS AND ANALYSIS}

\section{A. The basic situation of physical exercise for the elderly in wuchang district}

Through the statistics and analysis of the questionnaire, found that nearly $80 \%$ of the elderly in good health, the elderly are more or less suffering from some chronic diseases, such as: bronchitis, high blood pressure, waist dish outstanding, bone hyperplasia, etc. Adhere to old people in the square dance exercise the body health is good, according to the data of questionnaire showed that the elderly in the experimental group veteran generally between 3-5 years, some veteran in more than 10 years, and the number of weekly exercise in 3-4 times or more than 5 times, show that these exercisers love of square dance movement, they will be according to their own situation to choose exercise time and exercise, when movement appeared in the process of breathing, heartbeat accelerate slightly, the phenomenon such as sweating slightly, most people will stop exercising, pay attention to rest. Long-term adherence to the old people in the square dance exercise less appear the phenomenon such as falls and broken bones, that with exercise physical health a lot better than before, after health improved, also ease symptoms, and square dance movement will be as a lifelong sports stick to it.

\section{B. Reaction speed test results and analysis}

\section{1)Reaction speed}

Reaction speed is the ability of the body to respond to various stimuli. For example, a sprinter takes the time from the start to the start, the basketball player's quick response to a moment of change on the court. For middle-aged and elderly people, the faster response rate can effectively reduce the risk of injury. 
2) Test results and analysis

TABLE II EVALUATION TABLE OF THE ELDERLY RESPONSE IN WUCHANG DISTRICT

\begin{tabular}{|c|c|c|c|c|c|c|c|}
\hline Age & Sex & Group & $\mathrm{X} \pm \mathrm{s}$ & $\begin{array}{c}\text { Extellence } \\
(\%)\end{array}$ & Fine(\%) & Pass(\%) & Fail(\%) \\
\hline \multirow[t]{2}{*}{$55-59$} & Female & $\begin{array}{l}\text { Experimental } \\
\text { Group }\end{array}$ & $0.513 \pm 0.066$ & $67 \%$ & - & $33 \%$ & - \\
\hline & & ControlGroup & $0.738 \pm 0.063$ & - & $33 \%$ & $33 \%$ & $34 \%$ \\
\hline \multirow[t]{2}{*}{$60-64$} & Female & $\begin{array}{l}\text { Experimental } \\
\text { Group }\end{array}$ & $0.66 \pm 0.084$ & $33 \%$ & $33 \%$ & - & $34 \%$ \\
\hline & & $\begin{array}{l}\text { Control } \\
\text { Group }\end{array}$ & $0.999 \pm 0.075$ & - & $33 \%$ & $34 \%$ & $33 \%$ \\
\hline \multirow[t]{2}{*}{$65-70$} & Female & $\begin{array}{l}\text { Experimental } \\
\text { Group }\end{array}$ & $1.334 \pm 0.078 *$ & - & - & - & $100 \%$ \\
\hline & & $\begin{array}{l}\text { Control } \\
\text { Group }\end{array}$ & $1.432 \pm 0.095$ & - & - & - & $100 \%$ \\
\hline
\end{tabular}

Note: ${ }^{*} \mathrm{P}<0.05$ showed significant difference between the same agegroup and the experimental group and the control group.

To evaluate the evaluation criteria of the national standard manual (middle and old people) on the selection response. As can be seen from table 2, there is a significant difference between the age group and the same age group and the control group. Reactions of experimental group is significantly higher than the control group, therefore, insist for a long time to square dance exercise can effective training in old people of the central nervous system, shorten the reaction time, thus improve response ability.

\section{Balancing ability test results and analysis}

1) Balance

Balance is the objective performance of human balance function strength, is the People's Daily life one must possess the basic ability in labor, it to keep the smooth, elegant, harmonious and safe action has important significance. Because of safety concerns, this test is not closed on one foot.

2) Test results and analysis

TABLE III NO STANDING TEST RESULTS

\begin{tabular}{|c|c|c|c|c|c|c|c|}
\hline Age & Sex & Group & $\mathrm{X} \pm \mathrm{s}$ & Extellence(\%) & Fine(\%) & Pass(\%) & Fail(\%) \\
\hline \multirow[t]{2}{*}{$55-59$} & Female & $\begin{array}{l}\text { Experimental } \\
\text { Group }\end{array}$ & $35 \pm 10$ & $67 \%$ & $33 \%$ & - & - \\
\hline & & Control Group & $18.3 \pm 10.8$ & $33 \%$ & $34 \%$ & $33 \%$ & - \\
\hline \multirow[t]{2}{*}{$60-64$} & FemaLe & $\begin{array}{l}\text { Experimental } \\
\text { Group }\end{array}$ & $17.3 \pm 8$ & - & $100 \%$ & - & - \\
\hline & & Control Group & $8.3 \pm 8.2$ & - & $33 \%$ & $33 \%$ & $34 \%$ \\
\hline \multirow[t]{2}{*}{$65-70$} & Female & $\begin{array}{l}\text { Experimental } \\
\text { Group }\end{array}$ & $7.5 \pm 6.6$ & - & $50 \%$ & $50 \%$ & - \\
\hline & & ControlGrOup & $9 \pm 6.7$ & - & $50 \%$ & - & $50 \%$ \\
\hline
\end{tabular}


Note: ${ }^{*} \mathrm{P}<0.05$ showed significant difference between the same age group and the experimental group and the control group.

You can see from table 3, the subject, the experimental group don't close the standing on one foot than the control group obviously stand a long time, and the elderly in different ages don't close the standing on one foot is also different. Same age and gender in the experimental group and control group with significant difference between the average reaction time of the 65-65, for example, the same age group with significant difference between experimental group and control group. In the experimental group, the balance ability was better than the control group. This suggests that the long-term adherence to square exercise can delay the decline in the balance of elderly people, and can reduce the incidence of fracture and wrestling.

\section{Coordination ability test results and analysis}

1) The coordinated ability

Coordination is to point to in the process of physical movement, adjust and comprehensive body's ability to each part of the action, it is a kind of comprehensive ability, sensitivity, speed, balance, flexibility, and other physical quality is an organic whole, fully reflects the central nervous system control and regulation functions of muscle exercise capacity.

2) Measurement results and evaluation

TABLE IV TEST RESULTS OF HANDS COORDINATION ABILITY

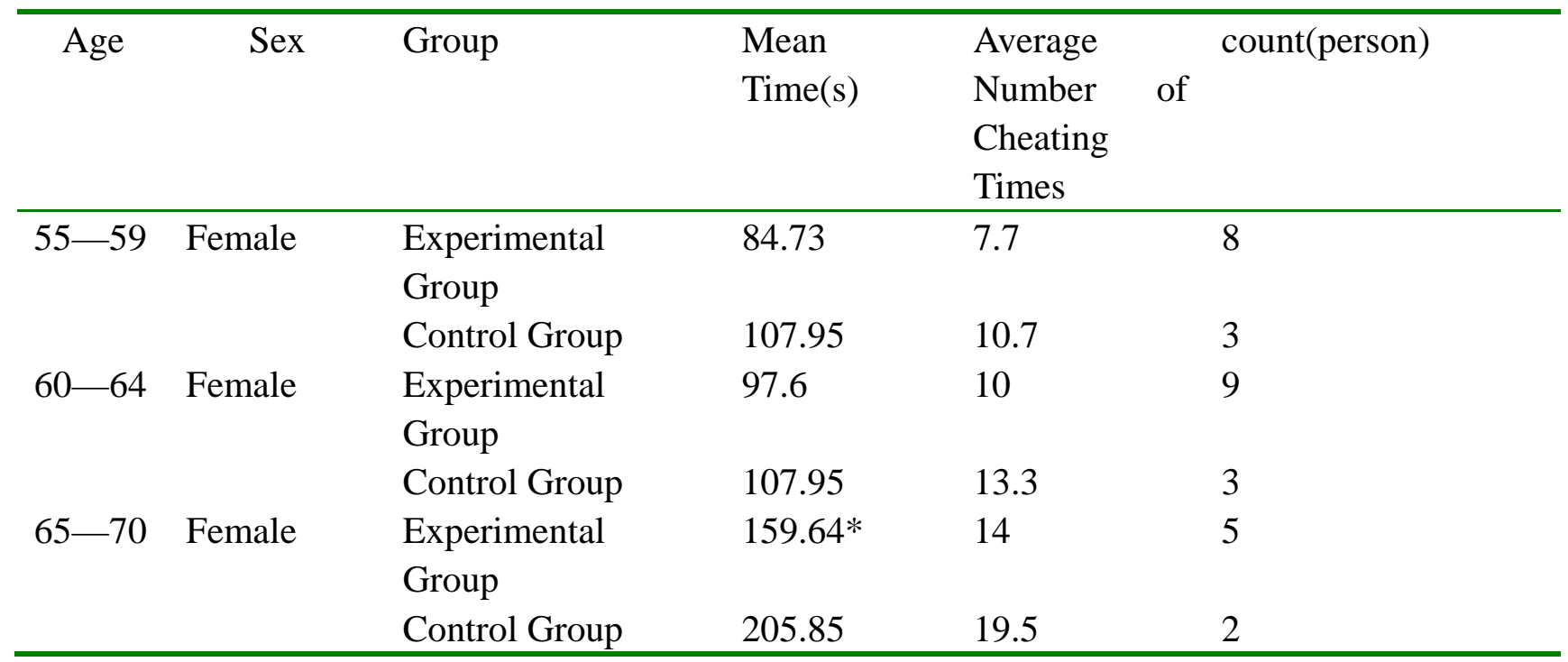

Note: $* \mathrm{P}<0.05$ showed significant difference between the same age group and the control group. $* * \mathrm{P}<0.01$ was significantly significant.

Two record test data, respectively according to the data analysis of the available average and the number of cheating mean value, and selects the optimal average data to evaluate the manifestation of the experimental group and control group in terms of balance. According to table 4 can be seen that the experimental group in hands coordination ability tests, when average and the number of cheating was better than control group, on average in 65-65, for example, with age, gender, when average between experimental group and the control group with very significant difference. As you can see derailed testing times average, at the age of 55 to 59 years old and 60-64 in the two age groups, the experimental group and control group have significant difference, the experimental group than the control group obviously fewer mistakes by tester. Therefore, it can be seen that the long - term square dance exercise has a positive effect on the coordination ability of the elderly and the elderly, and can effectively help the elderly to improve the flexibility 
of coordination and movement.

\section{IV CONCLUSIONS AND RECOMMENDATIONS}

A conclusion

1) Most insist to take exercise in old people, to participate in the square dance movement has great significance on their physique, physical health is better than before, the point of view, there is change, willing to expand the social network. There are many older people who believe that proper participation in sports can also prevent alzheimer's disease and delay the aging process.

2) The experimental group showed significant difference compared with the control group. Square dancing can enhance the coordination and rapid response of the motor nerve and muscle system. It can effectively help the elderly to prevent fracture and wrestling and avoid unnecessary injuries.

3) The square dance movement has a positive effect on the balance ability of the elderly. Studies have shown that older people who exercise often have a certain difference in their balance abilities than those who don't. Therefore, long-term adherence to square dance exercise can delay the decline of the balance ability of middle-aged and elderly people, and can reduce the incidence of fracture and wrestling.

4) Square dance can effectively enhance the coordination ability of middle-aged and old people. There was a significant difference in coordination ability between the experimental group and the control group. Square dance movement need effective cooperate with upper and lower limbs, insist for a long time to the coordination of the old people in the square dance training can improve ability, can effectively help the elderly to improve the flexibility of body coordination and action.

\section{B. suggest}

\section{1) Practice and combine}

In the middle aged people in the square dance exercise, most are based on the success of the game to judge the effect of each exercise. Such excessive games appear different degree of sport fatigue, if do not pay attention to proper rest and maintenance, the fatigue will form the sports injury, not only did not reach the fitness effect, on the contrary, will cause harm to the body. Due attention to rest, work and rest.

\section{2) Strengthening of quality practice}

In keeping with the practice of square dancing, some specific exercises can be added in order to enhance the reaction time, balance ability and coordination ability. In the development of quality training, we should train the ability of a variety of people, how to carry on the simple footwork exercises, one leg exercises and lower limb strength training, footwork exercises need body up and down, can not only develop the strength of lower limbs, also can effectively enhance the elderly of reaction time, balance, coordination, has a significant meaning to the prevention of falls and broken bones.

\section{3) Considerations}

The elderly should choose according to their own physical condition and interests sports, and follow the principle of step by step, at the beginning of the exercise intensity should be small, time also shoulds not be too long, with the improvement of physical ability and then gradually. At the same time, we should constantly monitor ourselves, observe our health and function during exercise, prevent excessive fatigue and reduce sports injury. And persevering, to achieve the goal 
of delaying aging.

\section{ACKNOWLEDGMENTS}

${ }^{1}$ Fund program:Provincial Teaching Research Project of Hubei provincial higher education institutions in 2016,Fund No.:2016445.Humanities and Social Sciences research project of Hubei Provincial Education Department.Fund No.:17G090.Scholl-level Teaching\&Research Subject:Teaching Design and Practice on Collegs Sports”Turnover Class”Fund No.:2016Z07

\section{REFERENCES}

[1]Xinhua Li. The physiological characteristics and scientific fitness of the elderly in the trial theory [J].Journal of sport.1999, (01)

[2]Haiying Xu. The study of physical exercise on improving the physique of middle-aged and old people [J]. Journal of anshan normal university, 2010. 204, 12 ( 2 ) : 84 - 87

[3]Longfei Zhang. A review of the health effects of square dance in the elderly [J]. Journal of jiangxi financial workers university, 2006, (19)

[4]Dajun Chen. Sports therapy and health rehabilitation function of square dancing [J]. Journal of Shanghai sports institute,1997, 21

[5]Xundan Hu. The study of the exercise of the square dance in the health of the elderly in China [J]. Swordnam literature: classical reading,2011, (10)

[6]Chunmei Wang. Experimental study on improving the sensitivity of square dancing [J]. Shandong sports technology,2001. 6, 23 (2) : 26-27 